\title{
Educação, pesquisa e consciência epistemológica: uma breve reflexão em torno ao pensamento de Popper e Boaventura Santos
}

\author{
Norberto Mazai* \\ O verdadeiro problema do conhecimento, portanto, \\ coincide com a questão sobre a relação \\ entre sujeito e objeto (Hessen, 2003, p. 69).
}

\section{Resumo}

\begin{abstract}
Este artigo busca apresentar, ainda que de modo sucinto, a relação entre a educação, a pesquisa e a consciência epistemológica, tendo como aporte as ideias de Karl Popper e de Boaventura de Sousa Santos. Augura-se evidenciar caminhos na perspectiva de provocar uma reflexão para novas práticas educativas a partir de contribuições no campo epistemológico e educacional. Discute-se a construção e a importância da pesquisa na educação como projeto educativo emancipatório, focalizando a busca por uma emancipação do indivíduo por meio da pesquisa e da educação.
\end{abstract}

Palavras-chave: Boaventura. Ciência. Educação. Pesquisa. Popper.

\section{Considerações iniciais}

O conhecimento tem sido tema pertinente no debate educacional, o que faz com que as teorias epistemológicas que tentam explicá-lo tenham profundas implicações nas formas de concepção teórica e de atuação prática na educação. A imbricação entre conhecimento e educação é uma relação dual. Se por um lado, pelo fato de a educação ser uma prática humana intencionada, reforça-se a ideia do conhecimento como centralidade da educação, pois ela necessita do conhecimento

\footnotetext{
Recebido: 15/02/2016 - Aprovado: 07/07/2016

http://dx.doi.org/10.5335/rep.v23i2.6538
}

Doutor em Educação pela Universidade de Brasília. Docente do Instituto Brasiliense de Direito Público e do Centro Universitário de Educação Superior de Brasília. E-mail: derphilosopher@gmail.com 
para significar seu rumo, uma vez que não pode se dar como prática puramente mecânica, transitiva, pautada pela doxa - senso comum. Aqui fica evidente a necessária vigilância crítica perante o fazer educacional. De outro, a educação é uma prática que produz conhecimento, pois tem por principal tarefa a construção de novos conhecimentos, assim como sistematizar e socializar os já disponíveis. Isso se dá por meio da pesquisa.

Essa tem sido, grosso modo, a concepção epistemológica que caracteriza os tempos modernos e que se traduz de forma multifacetada nas diversas tendências pedagógicas que marcam o cenário educacional. No entanto, quando se fala em pesquisa em educação, podemos perceber dois níveis distintos. Um de caráter mais metodológico, que diz respeito à questão de como se pode pesquisar em educação, e outro que aborda a questão sobre as condições de possibilidade de uma pesquisa no campo educacional e compreende a dimensão teórica (filosófica e científica).

Nas linhas que seguem, não pretendemos oferecer uma receita de como fazer uma pesquisa ideal ou escolher a melhor metodologia, mas, sim, procurar problematizar e apresentar indicações de caminhos, como também tecer, ainda que de forma embrionária, um quadro formado de elementos sucintos extraídos do pensamento de Karl Popper e Boaventura de Souza Santos a fim de balizar alguns pressupostos para se pensar em uma educação pautada em bases epistemológicas sérias, distinta daquela educação ligada ao senso comum.

\section{A natureza da pesquisa: algumas notas}

No campo educacional, a pesquisa distingue-se, do ponto de vista mais tradicional, grosso modo, em duas grandes esferas, a empírica e a teórico-bibliográfica, a qual buscamos defender ao longo deste trabalho.

Indiscutivelmente, a pesquisa empírica trabalha com o fenômeno educativo, almejando investigar temáticas e problemas que surgem das práticas educativas desenvolvidas por sujeitos inseridos em determinados espaços socioculturais, de caráter institucional ou não. Ela está associada ao fazer pedagógico dos envolvidos no processo todo desse fazer. Tal pesquisa pode debruçar-se sobre várias temáticas, como o cotidiano escolar, o currículo, a relação entre professor e aluno, a formação continuada de professores, como entre tantos outros temas.

A pesquisa teórico-bibliográfica, que ensejamos defender como meio de trabalho, reporta-se a um âmbito nitidamente conceitual, dizendo respeito, geralmente, ao processo de reconstrução e análise de teorias e conceitos de um determinado autor, obra e/ou tradição intelectual. A formulação do problema, nesse modelo de pesquisa, embora não ignore totalmente a situação educacional cotidiana, concentra- 
-se sobre o universo bibliográfico do autor ou da tradição pesquisados. Problemas como autonomia, autoridade, construção do conhecimento na criança, a imagem de sujeito na história da educação e da sociedade são temas típicos de investigação, por exemplo, em autores como Rousseau e Piaget e em teorias iluministas e construtivistas da educação.

Podemos argumentar que uma das diferenças entre essas duas formas de pesquisa consiste na seguinte ideia: a empírica prima pela investigação de problemas educacionais atuais, concentrando-se, por exemplo, no impacto que eles exercem no processo educativo como um todo, sem ter a obrigação de tratar sistematicamente de um autor ou de problemas ligados à tradição das teorias pedagógicas. A pesquisa teórico-bibliográfica, por seu estatuto, considera o diálogo com autores e teorias, da atualidade ou do passado, o centro de sua investigação, formulando problemas a partir desse diálogo. Assim, uma das diferenças entre as formas de pesquisa apresentadas é que a primeira vê-se descompromissada de uma investigação de caráter nitidamente conceitual, sem ter que se reportar à história das teorias pedagógicas, a segunda, necessariamente, sedimenta-se nesse aspecto, como já pontuamos. Se o grande desafio da primeira repousa em como manter a investigação de um problema educacional da atualidade em diálogo crítico com aspectos da tradição pedagógica ou filosófica passada, o desafio da segunda é buscar atualizar a própria tradição.

Esses apontamentos podem nos conduzir a duas hipóteses importantes. Por um lado, quanto maior for o vínculo sistemático da investigação de problemas educacionais atuais com a tradição intelectual e, em especial, com as teorias pedagógico-filosóficas, mais condições de esclarecimento obter-se-á sobre a complexidade da problemática atual. De outro, o vínculo sistemático da tradição com problemas educacionais da atualidade permite-lhe a abertura para novos problemas e caminhos e, por conseguinte, uma reestruturação de seu próprio conteúdo. Esse viés nos descortina algo sobre a importância de se estudar os clássicos, mostrando sua atualidade e autoridade a partir do confronto com problemas e situações presentes.

Apesar dessas diferenças esboçadas, tanto a pesquisa empírica quanto a teórico-bibliográfica apresentam em comum o fato de serem processos de construção do conhecimento e, como tal, necessitam oferecer um nível coerente e adequado de reflexão e articulação conceitual sobre o problema investigado. Um dos desafios ou entraves da pesquisa empírica é a reflexão sobre os dados oriundos dos levantamentos e das observações de campo, já o da pesquisa teórico-bibliográfica é a associação da produção conceitual com a realidade.

Evidencia-se, então, um dilema epistemológico, isto é, pesquisas de natureza teórica precisam ter um mínimo de senso de realidade e pesquisas de natureza 
empírica, um mínimo de senso conceitual reflexivo. Diante do exposto, queremos deixar claro que o dado empírico não é já por si mesmo realidade e nem o conceito é sinônimo imediato de reflexão. Ambos precisam deixar claro tanto o caráter reflexivo pretendido como a própria realidade que constroem, tendo como ponto de partida a pergunta. O professor e filósofo Hans-Georg Flickinger juntamente com Rohden observam que o perguntar perpassa por um aprendizado do próprio ato de perguntar, delineando o processo de compreensão. Assim afirmam os autores:

Trata-se aqui, naturalmente, de uma lógica do perguntar, desvinculada das condições do conhecimento objetivo, porque não se pergunta para se confirmar o que se sabe, senão para proporcionar a si mesmo e ao desconhecido um mostrar-se que o preserve e exponha simultaneamente. Prevalece aqui, portanto, o perguntar sobre o responder. E o destino de cada debate vindo após uma determinada apresentação depende inteiramente da pergunta que o abre. O mesmo dá-se no encontro entre duas pessoas. É a postura inicial de cada um que determina o aparecer da outra, no seu horizonte interpretativo. O compreender exige, por isso, em primeiro lugar, o aprendizado de como perguntar, a saber, de como preservar, na pergunta, a alteridade, isto é, o outro na sua diferença, dentro do próprio horizonte do encontro (FLICKINGER; ROHDEN, 2000, p. 46).

Toda pesquisa, portanto, que se furtar também ao ato profícuo do perguntar está fadada ao fracasso e, ainda, corre o sério risco de cair na frouxidão epistemológica. Assim, a pergunta a que nos referimos não é aquela que aceita respostas prontas, rasteiras, impostas pela cultura imediatista e imagética da atualidade, que, em sua grande maioria, castra a aptidão para a problematização, para a crítica, para o diálogo e, por fim, para o espanto, característica marcante do processo da pesquisa.

\section{0 problema de pesquisa e a escolha epistemológica}

Um dos pontos mais difíceis da pesquisa é, sem dúvida, a delimitação do problema. Essa delimitação requer noções preliminares sobre a natureza e a metodologia da pesquisa. A delimitação do problema a ser investigado sempre é o recorte de uma totalidade maior e a questão é como operar esse recorte, extraindo a parte de um todo maior, focalizando-a minuciosamente e, depois, repondo-a novamente naquela totalidade. Por exemplo, no campo da pesquisa educacional, poder-se-ia considerar como totalidade maior a educação como um fenômeno sociocultural e a investigação de problemas na formação do sujeito da educação como recorte daquela totalidade maior.

Se aspectos de ordem teórica (epistemológica) são considerados decisivos na delimitação do problema, também não se podem ignorar os fatores de ordem afetivo-morais, tendo que considerar, portanto, as próprias motivações existenciais 
que interferem na escolha deste ou daquele problema. Nesse sentido, poderíamos levantar o seguinte argumento: a produção do conhecimento humano está vinculada, de uma forma ou de outra, a interesses de ordem cognitiva, moral e estética, influenciando na escolha e na delimitação do problema. Quanto mais clareza o pesquisador tiver sobre esse suposto vínculo, mais condições ele terá de ser sujeito de sua própria pesquisa e, por conseguinte, conquistar autonomia no processo de construção do conhecimento.

Conhecer filosoficamente um objeto é questionar sua origem, realidade e destinação. Idealiza-se o objeto, tentando otimizar uma imagem ideal dele, como ele deveria ser, a partir do levantamento racional de suas características, formas e funções. Cria-se dele um modelo mental, no qual o objeto toma a forma ideal ou apropriada às suas condições e especificidades, estabelecidas pelo ideal de ser. $\mathrm{Na}$ filosofia, a verdade é idealizada e o conhecimento proposto, a visão do mundo é extraída a partir da concepção lógica da natureza das coisas, não diretamente dos fatos.

Esse tipo de conhecimento procura o sentido maior, a justificação, as possibilidades e alternativas de interpretação a respeito do objeto de interesse. Procura compreender e criticar a realidade em seu contexto universal; sua preocupação é a autorreflexão do espírito sobre a razão do seu comportamento, aspirando uma inteligência geral, ideal, a uma ótica racional de mundo.

Nesse sentido, tendo como bojo de reflexão todo o exposto, julgamos estar engessados em um dilema, a saber: qual modelo epistemológico abordar em nossas pesquisas? Diante dessa indagação ninguém pode furtar-se.

\section{0 aporte popperiano: um recorte}

As reflexões críticas acerca dos fundamentos da ciência são elaboradas há muito tempo. Podemos afirmar que filósofos e cientistas ${ }^{1}$ sempre buscaram alcançar a arké adequada do que vem a ser o saber científico, como ele procede, em que consistem o seus métodos, como atingir resultados e qual a sua credibilidade intelectual.

A constituição histórica de uma teoria da ciência deu-se no decorrer da década de 1920, quando alguns filósofos e cientistas reuniram-se em torno da pessoa de Moritz Schlick, ${ }^{2}$ em Viena, Áustria. Nascia, assim, o Círculo de Viena e, com ele, o empirismo lógico. Os representantes do Círculo de Viena caracterizaram-se pela autocrítica e por uma honestidade intelectual ilibada. No entanto, não podemos colocar Popper no rol dos pensadores do Círculo de Viena ou, se preferirmos, como um empirista lógico. ${ }^{3}$ 
Quando a ideia de método científico universal foi questionada, foi necessária uma reformulação acerca de quais eram os limites da ciência e o que tornava uma teoria científica ou não, depois da tentativa do Círculo de Viena ${ }^{4}$ com o empirismo lógico, com sua exigência de clareza e precisão e o critério da verificabilidade, com o objetivo de validar uma teoria científica. Foi nec-essário, então, um novo olhar a respeito dos limites da ciência, uma vez que o neopositivismo não foi capaz de dar as respostas, tornando ainda mais dogmática a atividade científica.

Surge então Karl Popper, filósofo, físico e matemático, que criticou o critério de verificabilidade e propôs como única possibilidade para o saber científico o critério da falseabilidade. Como formou-se em Viena, o filósofo partilhou com os positivistas lógicos o interesse pelos fundamentos da ciência. Logo, segundo Losee (2000, p. 222), Popper encarava a história da ciência como uma sequência de conjecturas, refutações, conjecturas revistas e refutações adicionais.

Karl Popper é, indubitavelmente, um dos mais influentes e significativos filósofos da ciência de nossa época, além de ter sido um grande intelectual liberal. A chave articuladora de todo o seu pensamento reside na epistemologia e é o falibilismo o ponto nodal de sua reflexão sobre o conhecimento científico. Essa é, por sua vez, a primeira grande lição que nosso pensador tira da revolução relativista: no domínio das ciências empíricas, naturais ou sociais, nenhuma teoria pode ser considerada uma aquisição definitiva do espírito humano, isto é, nenhuma teoria pode ser considerada como definitivamente estabelecida ou definitivamente aprovada. Em outras palavras, nenhuma teoria está livre do risco de que, dentro do seu campo de aplicação, venham a surgir problemas que ela não seja capaz de resolver e que nos obriguem a procurar a substituição por uma teoria melhor, capaz de resolver tanto esses novos problemas como os problemas que a velha teoria já resolvia. Desse modo, uma teoria científica deve sempre ser considerada como uma conjectura, uma hipótese, passível de ser revisitada, revisada ou, inclusive, abandonada à luz de novos desenvolvimentos conceituais, pois, como afirma Popper (2008, p. 35), nossas mentes abrigam preconceitos inculcados pela tradição e outras influências maléficas que perverteram nossas mentes originariamente puras e inocentes.

Se as nossas teorias nunca podem ser inteiramente confiáveis, se elas sempre podem acabar se mostrando falsas ou insuficientes, o que fica é a permanente vigilância crítica sobre elas. É justamente isso que estamos procurando enfatizar com este estudo. Mas, não seria essa nossa tentativa também passível de falseabilidade? Cremos que não, dado que o intuito maior é buscar evidenciar o aporte de Popper e Boaventura no balizamento de uma possível educação pautada, alicerçada e demarcada por uma consciência epistemológica aguçada e não como uma ciência meramente procedimental. 
A atitude crítica de vigilância nos exige mostrar que temos boas razões para duvidar daquilo que estamos questionando. Não se trata meramente de insistir que todas as nossas teorias são passíveis de falseabilidade e que, portanto, sempre terminarão por surgir dificuldades insolúveis para elas. Popper nos recomendou a vigilância falseacionista como uma resposta à constatação falibilista de que nossos meios de prova são sempre limitados e insuficientes para produzir uma justificação concludente de nossas teorias. Sob outro prisma, poderíamos então indagar: não seria esse recurso de vigilância também limitado? Talvez, pois para sermos mais críticos temos que aceitar pelo menos parcialmente um conhecimento primário. Um racionalismo crítico deve estar consciente dessa possibilidade transformadora.

Para Popper, uma teoria científica deve sempre ir além dos dados empíricos disponíveis, desde que seja refutável. Se tudo o que pode acontecer for compatível com a teoria, então ela deixa de ser uma teoria científica e passa a ser uma questão de fé, ou uma ideologia. Não seria esse o grande problema de nossa educação? Uma educação alicerçada em uma ideologia, no senso comum? Que não é problematizada em toda a extensão do termo? Não estaria à educação sendo reduzida a modismos, à reprodução de ideias já prontas e estabelecidas, cujo fim é a lógica mercadológica da atualidade?

É nesse sentido que se faz pertinente o aporte de Karl Popper para viabilizarmos uma nova ideia de construção de conhecimento no campo educacional. Ideia que não esteja vinculada a preconceitos epistemológicos, mas como possibilidade de repensarmos e resgatarmos o próprio sentido de educação e de pesquisa no meio pedagógico.

\section{Boaventura e a questão do senso comum}

Ao iniciar este tópico, gostaríamos de evidenciar a complexidade e a extensão da problemática, já que representa um desafio de grande proporção, o que nas próximas linhas, do ponto de vista epistemológico, filosófico e pedagógico, não poderá ser desenvolvido satisfatoriamente. Aqui, a reflexão não busca o ineditismo, mas o alinhavar de algumas das ideias do pensador em questão e sua contribuição para o entendimento da problemática suscitada em nosso trabalho.

Boaventura faz uma diferenciação abrupta entre ciência e senso comum, ao afirmar que:

[...] O senso comum, o conhecimento vulgar, a sociologia espontânea, a experiência imediata, tudo isto são opiniões, formas de conhecimento falso com que é preciso romper para que se torne possível o conhecimento científico, racional e válido. A ciência constrói-se, pois, contra o senso comum, [...]. É pois, um pensamento necessariamente conservador e fixista (SANTOS, 1986, p. 31-32). 
$\mathrm{Na}$ verdade, o que o pensador está querendo frisar é que a ciência, para se firmar, tem de romper com o senso comum. Não há consciência sólida porque desdenha das estruturas que estão para além da consciência, mas, por isso mesmo, é exímio em captar a profundidade horizontal das relações conscientes entre pessoas e entre pessoas e coisas (SANTOS, 1986, p. 40).

Pensamos que aqui se formaliza uma das proposições centrais tematizadas pelo filósofo, a de que, quando assumimos uma única e indissolúvel postura, corremos sempre o risco de inviabilizarmos a nossa condição de seres não acabados; justamente, porque estamos inseridos em um ininterrupto processo de construção existencial, que está em estreita relação com o universo. $\mathrm{O}$ homem necessita sair de si para desenvolver-se como homem e, assim, poder ampliar o seu conhecimento bem como sua eficácia. No fundo, o que o homem busca é o enobrecimento de seu interior que se dá na tensão entre razão e ação. Essa assertiva delineia a diferença entre uma educação voltada para uma consciência epistemológica coisificada como a do senso comum, fechada em si mesma e em seus arcabouços.

O ser humano não é algo dado, pronto, engessado ou fixo. O homem é construído mediante suas relações, não se bastando a si mesmo como uma máquina com suas "arruelas e contrapesos", capaz somente de autorregulação.

Implícita, aqui está, também, a relação pensamento e ação na educação. $O$ pensamento só torna-se possível na relação com o exterior. Não é o mundo que define a perspectiva do homem, mas é a razão que define a perspectiva do homem. Somente pela razão é que o homem consegue definir o que ele é no mundo e, consequentemente, configurar a realidade. Para tanto, a razão precisa estar vigilante, falseando as investidas inconsistentes do senso comum.

Apontados esses significativos elementos, poderíamos ainda suscitar os seguintes questionamentos: não correria o homem, no ato do falsear, o perigo de perder-se ao sair de si mesmo? Não seria exatamente no perder-se, no falsear-se, que poderíamos nos achar e reafirmarmo-nos? Essas diferentes percepções denotam a extraordinária capacidade do homem de sair de si mesmo e, ao mesmo tempo, de poder regressar. É justamente aqui que reside uma ligação profícua entre o pensamento de Popper e de Boaventura, isto é, ambos delineiam explícita ou implicitamente a real necessidade de uma consciência epistemológica na educação, para que ela não caia em reducionismos.

É nessa esfera de unidade e diversidade que ocorre, também, a dialética da totalidade, ou seja, cada indivíduo é uma totalidade que reflete a totalidade maior, o mundo. Quanto mais o homem estiver se desenvolvendo em uma perspectiva múltipla, maior será a riqueza de seu mundo interior e a possibilidade de ampliar a sua concepção de mundo. 
Se compreendermos o hodierno escolar como um espaço de construção e de possíveis tensões, o pensamento de Boaventura suscita, dentre outras possibilidades, a necessidade de um esforço de identificar as ausências, potencializar as emergências e promover o diálogo recíproco entre os saberes. Dessa forma,

[...] a sala de aula tem de transformar-se ela própria em campo de possibilidades de conhecimento dentro do qual há que optar. Optam os alunos tanto quanto os professores e as opções de uns e de outros não têm de coincidirem são irreversíveis. As opções não assentam exclusivamente em ideias já que as ideias deixaram de ser desestabilizadoras no nosso tempo. Assentam igualmente em emoções, sentimentos e paixões que conferem aos conteúdos curriculares sentidos inesgotáveis (SANTOS, 1986, p. 19).

Assim sendo, o espaço da sala de aula como esfera privilegiada da formação de consciência crítica busca sentidos para a aprendizagem na experiência histórica e nas subjetividades em estreita relação de interação no processo educativo e, para tanto, coloca em discussão não só o conhecimento/informação, mas também os interesses em jogo e as condições históricas de sua produção.

\section{Considerações finais}

A educação, em todos os tempos da história humana, sempre foi um desafio. No entanto, essa realidade assume uma conotação tão exigente quanto desafiadora. Isso nos leva a suscitar aqui, no mínimo, dois problemas que podem estar vinculados à educação: o sujeito que sabe ou que pensa que sabe de tudo um pouco (saber inócuo) e o especialista extremamente mergulhado em seu campo específico, sem abertura (verticalismo pedagógico), que não passa de um especialista idiota. Ambos assumem uma perspectiva em que nada se assemelha a uma formação voltada à conscientização epistemológica séria, vinculada na relação dialógica interior e exterior, que promove a autonomia tanto do educador quanto do educando na realidade em que estão inseridos.

A educação de modo algum deve ser confundida tão somente com habilidades técnico-científicas de resolução de problemas, com o conhecimento enciclopédico dos livros, com a falsa erudição, que unicamente repete o pensamento dos outros sem uma reflexão apurada e diversificada, com saberes nada criativos ou arejados; nem tampouco, e sobretudo, ter apenas o intuito de ganhar e vencer na vida, de produzir e transmitir conhecimentos que atendam estritamente a essa necessidade ou aos slogans educacionais da moda. A educação transcende a esses elementos!

A educação aparece como algo global e totalizante. Ela visa, indispensavelmente, ao pleno desenvolvimento de todas as potencialidades da pessoa, esgotando todas as formas possíveis e impossíveis de formação, dialogando, suscitando 
problemas e hipóteses, ouvindo e desenvolvendo diferentes perspectivas, enfoques e estímulos emancipatórios, para que, na projeção e fundamentação de uma sociedade futura, possam-se engendrar novos homens, capazes de transcender toda e qualquer forma de ingenuidade e voluntarismo.

Muitas das proposições aqui desenvolvidas, mesmo que embrionariamente e sem ter a pretensão de ineditismo, mereceriam maior aprofundamento e ser desenvolvidas de uma forma mais orgânica. Entretanto, o objetivo maior não foi o de elaborar um tratado acerca da educação e da pesquisa sob o enfoque de Popper e Boaventura, pois essa não é, de forma alguma, a finalidade das ideias aqui alinhavadas, mas apenas propiciar algumas pistas para que os autores e a temática levantada possam ser retomados e refletidos dentro dos diferentes contextos que ora possam emergir e, em especial, no campo epistemológico educacional.

Diante do que foi apontado, cabe uma pergunta: quais as possíveis contribuições dos autores à educação e aos educadores do século XXI? Uma das contribuições seria a de retomar a pergunta pelo próprio sentido da educação, da pesquisa, do ser humano e da figura do professor na sociedade. O sentido máximo da sociabilidade e onde ela se alicerça. O questionamento de onde se encontra o professor que deveria ensinar sem adestrar, formar sem deformar, seduzir sem converter, impor-se sem oprimir, disciplinar sem obrigar.

Por fim, fica o convite para que outros levem adiante a chama que foi acesa. As bases iniciadas por Popper e Boaventura continuam em construção e, acertadamente, devem engendrar a atenção de múltiplos olhares, viabilizando o importante diálogo entre a tradição e a contemporaneidade sem cair em generalizações apressadas ou em ranços históricos e epistemológicos.

\section{Education, research and epistemological consciousness: a brief reflection around the thought of Popper and Boaventura Santos}

\section{Abstract}

The article aims to present, though in a concise way, the relation among the education, the research and the epistemological awareness taking into consideration Karl Popper's and Boaventura de Sousa Santos' ideas. It is intended to show ways in order to instigate a reflexion to new educational practices considering contributions in the educational and epistemological area. It also talks about the construction and the importance of the research in education as an educational and emancipatory project focusing the search for an emancipation of the individual by the research and education.

Keywords: Boaventura. Education. Popper. Research. Science. 


\section{Notas}

1 Como diz Popper, é a tradição do debate crítico.

2 Moritz Schlick, físico alemão (Berlim, 14 de abril de 1882 - Viena, 22 de junho de 1936), foi a figura central do positivismo lógico e do Círculo de Viena. Em 1922, assumiu a cátedra de Filosofia das Ciências Indutivas, em Viena. Logo no ano seguinte, ele assumiu a coordenação do grupo de filósofos e cientistas interessados em temas epistemológicos.

3, A sua relação com o Círculo de Viena foi uma relação de natureza crítica e de debate fecundo.

4 O Círculo de Viena surgiu, nas primeiras duas décadas do século XX, como um movimento em reação à filosofia idealista e especulativa presente e dominante nas universidades alemãs.

\section{Referências}

FLICKINGER, Hans-Georg; ROHDEN, Inácio (Org.). Hermenêutica filosófica: nas trilhas de Hans-Georg Gadamer. Porto Alegre: EdiPUCRS, 2000.

HESSEN, Johannes. Teoria do Conhecimento. Sâo Paulo: Martins Fontes, 2003.

LOSEE, John. Introdução histórica à filosofia da ciência. Tradução de Borisas Cimbleris. Belo Horizonte: Itatiaia, 2000.

. Conjecturas e refutações. Brasília: Universidade de Brasília, 2008.

SANTOS, Boaventura de Souza. Introdução a uma ciência pós-moderna. São Paulo: Graal, 1986. 